\title{
Reflections on the Evolution of Undergraduate Research at Primarily Undergraduate Institutions Over the Past 25 Years
}

Mitchell R. Malachowski, University of San Diego

\begin{abstract}
Undergraduate research (UGR) has grown in prominence and stature over the past 25 years as it has been embraced at institutions of all types. The enormous changes that have been made to support these endeavors have led to many success stories but also have created many challenges for faculty operationalizing these activities. In this article, the successes and challenges of institutionalizing UGR at primarily undergraduate institutions (PUIs) are described, and the concerns that still need attention are addressed. Assisting faculty in remaining student-oriented rather than becoming research-oriented, the primary reason to do research at PUIs and valuing the process of doing UGR along with the products of the work are probed. The creation of scaffolded, backward-designed, research-rich curricula is discussed, and some of the remaining challenges to institutionalizing UGR are considered.
\end{abstract}

Keywords: curriculum design, institutional culture, student orientation, student outcomes, undergraduate research

doi: $10.18833 /$ spur $/ 3 / 2 / 5$

The benefits to students and faculty of engaging in undergraduate research (UGR) are now widely accepted at institutions of all types (Osborn and Karukstis 2009). This has not always been the case, as in many disciplines there has been considerable resistance to including students in faculty scholarship. Twenty-five years ago, the author studied the educational literature on student learning, student outcomes, and student satisfaction, and considered it in relation to UGR activities with the goal of extracting evidence that supported the anecdotal comments on the importance of UGR made by many faculty at institutions of many types. Most compelling was the work of Alexander Astin, who described various features of student engagement in his influential What Matters in College books (Astin 1977, 1993). In those volumes, Astin outlined the relationships between students and faculty, examining how faculty affected the lives of their students. His conclusions, bolstered by an enormous amount of data,were foundational in the author's ongoing argument for the centrality of undergraduate research to supporting the interests and needs of the faculty while bolstering outcomes for students. Astin's arguments subsequently were supported by the work of many other educational researchers, and their writings have had a great impact on many who study undergraduate research (Boyer 1990; Kuh 2008; Kuh et al. 1991, 2015; Pascarella and Terenzini 1991). Although UGR has become more prevalent over the past 25 years, there are many unresolved issues that still deserve attention. This article reinforces some arguments that originated 25 years ago, updates others, and describes changes observed over the years in the world of UGR at primarily undergraduate institutions (PUIs), with the hope of demonstrating the evolution of UGR and highlighting the tremendous impact it has had on campuses, as well as describing some of the unresolved issues.

\section{Student-Faculty Interactions}

Prior to addressing its significance for students, consider why UGR is important for faculty. A case has been made that all faculty at PUIs should include students in their research (Malachowski 1997, 2003). This is still not the norm, so the argument is again presented here. One premise deduced from Astin's longitudinal data was that faculty 
could be placed into one of two camps: one with a research orientation and the other a student orientation. These camps reflected not only how faculty members spent their time but also their personal goals and values, as well as their interest in and accessibility to students (Astin 1993).

Astin found that the extent to which faculty were student oriented produced substantial effects on student outcomes and student satisfaction, whereas a research orientation led to some of the strongest negative impacts. Studentoriented faculty had tremendous positive impacts on student learning and outcomes, including quality of overall college experience, likelihood of graduating with honors, academic development, student perception of quality of instruction, and general education requirements. On the other hand, a strong faculty research orientation had a substantial negative effect on student outcomes, extending to satisfaction with the overall quality of instruction and college experience, graduating with honors, grade point averages, leadership development, and completion of bachelor's degree. As more and more faculty at PUIs spend more and more of their time engaged in research that does not include students, more faculty become entrenched in the research-oriented camp. Astin's results clearly showed that there was a substantial institutional price to be paid for a strong faculty emphasis on research, whereas having a strong student-oriented faculty paid rich dividends in the affective and cognitive development of students. So how does one retain student-oriented approaches while increasing the level of scholarship on campus? The obvious answer is engaging in UGR, which allows faculty to do what they are very interested in doing - research-while remaining student centered (Malachowski 1999). As one example, twenty-five years ago, the chemistry department at the University of San Diego (USD) asked faculty candidates for a teaching philosophy and a broad outline of their research interests. Now, a commitment to UGR begins in the hiring process. Candidates for faculty positions are expected to submit a research plan that includes how they intend to include students in their research programs, what equipment they will need to do the work, and how they intend to support their research students with external grants. Candidates without a carefully constructed UGR plan are at a serious disadvantage.

Over the past 25 years, almost every PUI in the country has increased the level of scholarship performed on campus and has higher expectations of faculty output. As a consequence, faculty now spend more of their time doing research, running the risk of becoming more research-oriented rather than student-oriented if they do not include students in their work. Jacobson (1992) has studied the phenomenon of "institutional drift" and has shown that changes to institutional mission almost always occur in the direction of the research university model, regardless of institutional type. USD has reduced the teaching load from eight courses per year to five courses per year, with some faculty teaching less by "buying out" courses from external grants. The reduction came with an explicit expectation for increased levels of scholarship, particularly productivity and publication. These changes have led to diminished engagement between faculty and students in those areas where UGR is not the norm with these changes leading to the negative consequences described by Astin.

The educational literature clearly shows the risks involved in supporting campus-wide teacher-scholar models that do not include students so the call is for all faculty at PUIs to involve students in their research. Preference in internal grants programs should be given to faculty who do UGR and embrace the engagement of students. In addition, larger merit pay increases should go to UGR-engaged faculty. Undergraduate research is a wonderful form of scholarship in that it melds the demonstrated academic needs of students and faculty interests for engagement in original scholarship. Faculty who participate in UGR should be supported at higher levels than those who do not include students in their research.

If Astin and others are correct, why don't all research faculty engage in UGR, and what are the barriers that exist to further incorporation of these activities? Common barriers described by faculty members include the limited capability of students to contribute to the work, the ability of faculty to make more research progress without student involvement, and the lack of adequate time or resources to make it worthwhile. However, the most significant barrier to including students in research is related to the vastly different cultures of each discipline (Eckel and Kezar 2003; Kotter 2012; Malachowski and Webster 2008; Nicols-Grinenko et al. 2017). In the natural sciences and the more experimentally oriented social sciences, working with students on research projects is widely accepted and commonly practiced, whereas this is not conventional in other disciplines. Research is a typically a collaborative endeavor in the sciences, whereas it is more of a solitary activity in other disciplines; including students in faculty work may not come naturally. These cultural issues are systemic and serve as the biggest barrier to campuses fully embracing UGR. Even as those faculty who do not engage in research retire, this issue will remain front and center, as effecting cultural transformation is difficult.

It is vital not only to reflect on the impact of UGR on disciplines, departments, institutions, and careers but also to ask what is occurring in areas where research is proliferating without student engagement (Malachowski 2001). UGR participants have pushed hard for the resources needed to substantially increase the amount of research performed at institutions, and certainly expectations for scholarship have been elevated even in areas where 
UGR has not taken root. Therefore, the UGR community, including CUR itself, is partly responsible for diminishing the quality of the undergraduate experience for students in areas where UGR is not the norm. Until UGR takes hold in all disciplines, students in areas without UGR will suffer the negative impacts as discussed by Astin (Malachowski 2010). It is believed that UGR is a vastly superior form of research at PUIs and that nonpracticing colleagues in other disciplines must be convinced of its benefits, even if it means explaining to them how to do their research. It also is critical for deans and provosts to recognize the vast difference in student outcomes in departments that do UGR when compared to those that do not and to take measures to support activities that enhance student learning associated with faculty research.

\section{Student Learning}

What are the drivers for scholarship on today's campuses? UGR is pursued for many different reasons, including benefits to the students, to the faculty, and more broadly, to institutions. One goal is for faculty to retain studentcentered approaches (Malachowski 2004). There are many who do not agree with the premise that UGR should be incorporated across all disciplines at PUIs. They argue that research should be faculty oriented and done in a way that allows faculty to make contributions to their disciplines, stay intellectually vigorous, increase job satisfaction and personal development, and inform their teaching. Although it may be a matter of degree, this article argues that student learning and outcomes matter the most.

There was a time when there was a great divide between faculty who engaged in research and faculty who did not. Now, however, with most faculty engaged in research, the new line of demarcation is between faculty who engage students in their research and those who do not. The latter group is product-oriented in its approach to research, rather than favoring a process-oriented approach (Malachowski 2006, 2012). The goals, expectations, and methodologies of these two groups are so vastly different that they work in parallel universes. The following is proposed as a mission statement for research at PUIs and comprehensive institutions:

Research performed on our campus is pursued primarily as a means to enhance the intellectual climate and for its positive impacts on student learning. In order to directly impact students, all faculty in all departments involved in scholarship should include students in their work. Secondary benefits to the faculty and the institution are also of importance, but enhancing student learning is of primary importance. Decisions regarding hiring, resource allocations, faculty loads and promotion and tenure decisions will be determined primarily by the impact of the research on student learning. (Malachowski 2004, 107)
It is suggested that campus-wide promotion and tenure documents also include this statement. In the chemistry department at USD, a promotion and tenure document describes the centrality of UGR to faculty research activities and how this standard is applied to all faculty evaluations. There are expectations for obtaining grants, giving presentations, and publishing, but no one is retained or promoted without a sizable number of students working in their laboratories or libraries. When these suggestions were first made in CUR Quarterly (Malachowski 2004), there were those who disagreed. CUR Quarterly published a counterpoint (Wenzel 2004) that outlined the cogent arguments against a focus on student learning.

Modification of departmental long-range plans also can help target specific goals. In addition, this can serve as the foundation for budget requests, facilities planning, curricular changes, and external grant submissions. These plans transmit signals to other departments that student-centered research activities are important. It is particularly useful to provide a rationale for student-centered research in the plan (Malachowski 2003). The USD chemistry department creates a rubric each year that estimates the number of anticipated publications, presentations, grants, student presentations, and equipment purchases. Most important, each faculty member determines planned contributions to departmental goals. This is an effective way for faculty to work together to meet collective goals.

\section{Research Impacts}

As research takes up more and more time (and resources), it is important to evaluate the impact of the move to more scholarship on college campuses on faculty commitment to teaching. Many faculty now do less classroom teaching than they did before the teacher-scholar model took over. Advocacy by CUR for increased scholarship has helped lead to institutional pressures, rewards, and new priorities that encourage and support more research. As faculty at four-year institutions redistribute their work priorities, UGR practitioners should continue to discuss its impact on their teaching and commitment to students (Malachowski 2010). In moving to a model in which many more faculty are involved in research, resources have been shifted to support these efforts. There are now more and more examples of the reallocation of funds for equipment, start-up, facilities, pretenure sabbaticals, and personnel that support the research enterprises. The pace of change may be quite different from one institution to another, but the literature makes clear that there is movement toward a research university model at many institutions.

Research of Fairweather $(2002,2005)$ regarding the relationship between research and teaching has shown that the institutional drift toward a research university model also includes merit pay increases, with greater numbers of publications trumping teaching activities at institutions 
of all types, including PUIs. Additionally, promotion and tenure documents have been modified to increasingly privilege research over teaching. All these factors favor the faculty member with a more research-intensive professional life at the expense of teaching and students. Faculty respond to these changes in predictable ways as they create an environment that leads to a more research-oriented institution. Faculty must continously guard against the possible detrimental impact on the quality of classroom teaching experiences that can result from these moves to more scholarship.

\section{Undergraduate Research Requirement}

UGR has exploded over the past 25 years as the benefits it brings to students, faculty, and institutions are better studied and understood. Along with these demonstrated benefits, UGR readily addresses some of the goals of higher education, such as preparing students for a career, exposing students to new ways of seeing the world, and importantly, teaching students critical thinking and problem-solving skills. UGR meshes well with what employers value most in their employees - the ability to innovate and help move a business forward through creative innovation (Hart Research Associates 2013; Malachowski 2013, 2017). The primary motive of most students at PUIs (and their families) is obtaining a bachelor's degree and finding employment and UGR prepares students extremely well for the workforce. On a more personal level, it helps students find passion and purpose.
Twenty-five years ago, the vast majority of UGR was done in the natural sciences and used the traditional science model of one-on-one mentored research, frequently in a laboratory setting. Arguments were made to include all disciplines, and the science mentorship model was broadened to include approaches common to other disciplines. As explained, there was a time when an argument had to be made for including UGR in all disciplines (Malachowski 1999). CUR at that time was not equipped to support all disciplines with fundraising or lobbying activities. The fight to include all disciplines in UGR activities has been successful as a research-across-the-curriculum movement has taken hold in many fields, and this is reflected in the current structure of CUR (see Table 1). However, the percentage of faculty in the humanities, education, engineering, and business who include UGR in their curricula continues to lag behind areas in which UGR has been a mainstay of the culture for many years.

As a consequence, attention should be focused on the intensity of the commitment of many departments to UGR. The transformational power of UGR argues for making it a requirement for all students across all disciplines (Malachowski and Dwyer 2011). The chemistry department at USD now requires UGR of all students. Implementation has created substantial challenges regarding resources and faculty time, however, transformation of the department has exceeded expectations. Although relationships with students have always been valued, there is now a richer set

\section{TABLE 1. Disciplinary Divisions in CUR}

\begin{tabular}{|l|l|}
\hline 25 years ago & \\
\hline Biology & Biology \\
\hline Chemistry & Chemistry \\
\hline Geology & Geosciences \\
\hline Mathematics & Mathematics and Computer Sciences \\
\hline Physics/Astronomy & Physics/Astronomy \\
\hline At-Large & At-Large \\
\hline & Arts and Humanities \\
\hline & Education \\
\hline & Engineering \\
\hline & Health Sciences \\
\hline & Psychology \\
\hline & Social Sciences \\
\hline & UGR Programs \\
\hline
\end{tabular}

Note $:$ CUR $=$ Council on Undergraduate Research; UGR $=$ undergraduate research 
of interactions with students that center around more intellectual issues. It is not simply faculty-student interactions that have changed; student-student interactions also have been enhanced, with an almost constant buzz now among students about their research activities. They help each other use instruments; talk about their research results; and discuss attending a meeting, writing up results, or preparing posters and presentations. Even Friday afternoons are filled with research activities and interactions. UGR should be just as essential to the curricula in all fields of study and should be required by all.

\section{Undergraduate Research Changes}

Many people believe that colleges and universities are immune or glacially slow to change, but this is far from the reality. One of the most important of these changes is the expectation that almost all faculty do research. The move to enhanced levels of scholarship at PUIs has not only altered how faculty use their time but also changed hiring decisions; resource allocations; teaching loads; promotion and tenure guidelines; facility planning; expectations for grant procurement; and, most important, the relationship between faculty and students. Campuses have embraced UGR for many reasons: as a way to attract talented students and increase retention, as part of diversity efforts, as a pathway to prepare more students for graduate school, as part of the activities of honors colleges, and as an approach to enhance the intellectual climate (Malachowski 2017). Engaging students in original scholarship is a time-intensive and expensive activity, but the outcomes are almost always powerful and positive. The designation of UGR as a highimpact practice (Kuh 2008; Kuh et al. 2015; Kuh and Kinzie 2018; Mayhew et al. 2016) also has fueled connection of UGR to institutional missions. The landscape has changed dramatically. Table 2 highlights how different campuses have become over the past 25 years as UGR has taken hold.

TABLE 2. Changes Impacting Undergraduate Research over the Past 25 Years

For the students:

- UGR has become a high-impact practice.

- Student support has increased, with programs such as REU, McNair, and Beckman.

- NCUR provides opportunities for student presentations.

- Travel funds to attend meetings are more common.

- Celebration days have proliferated.

- UGR journals are in place.

- Connections to community-based learning and international projects have formed.

- UGR is practiced in all disciplines.

\section{For the faculty:}

- Expectations for research are now part of faculty job descriptions.

- Start-up funds are part of job packages.

- Individual research labs are now very common.

- Travel funds to attend meetings are more common.

- Teaching loads have been reduced substantially at some institutions.

- Tenure and promotion documents frequently include UGR.

- Equipment at PUIs for research is more sophisticated and prevalent.

- Pretenure sabbaticals are possible.

- Research excellence awards and honors are common.

- Internal grants are more prevalent.

- Funding from NIH, NSF, and other agencies has increased for faculty at PUIs.

- Research-rich curricula are being explored.

- UGR is practiced more extensively in all disciplines.

For the institution:

- UGR is connected to institutional missions.

- Academic climate has been enhanced by UGR.

- Infrastructure has been enhanced to support research activities.

- New facilities support UGR activities.

- Academic support staff are commonly provided (grants managers, lab supervisors, and instrument technicians).

- Assessment of UGR is routinely practiced.

Note: NCUR = National Conference on Undergraduate Research; NIH = National Institutes of Health; NSF $=$ National Science Foundation; PUI = primarily undergraduate institution; REU $=$ Research Experiences for Undergraduates (NSF program); UGR = undergraduate research. 
Program assessment is now extensivelybecoming embedded in the work of those who study UGR (Laursen 2015; Laursen et al. 2010; Lopatto 2009, 2010; Seymour et al. 2004). Evaluations of many flavors of UGR have skyrocketed over the past 25 years as the UGR community has replaced anecdotal commentary with actual data. Funding agencies have fueled this change by expecting a level of evaluation that did not exist 25 years ago. Data-driven projects are now the norm, and there is no doubt this will remain important in the field of UGR.

\section{Curricular Impacts}

Without a doubt, the largest transformation over the past 25 years has been the incorporation of research approaches into the undergraduate curriculum. What was a simmering issue two decades ago has led to a sea change (Aikens et al. 2016; Alkaher and Dolan 2014; Awong-Taylor et al. 2016; Corwin, Graham, and Dolan 2015; Karukstis and Elgren 2007; NASEM 2015). The Institutionalizing Undergraduate Research Institutes of CUR and a series of CUR-connected NSF grants (with more than 700 institutions participating since 1997) have seen more and more institutions participate in the workshops as a means to explore how to embed UGR into their curricula (Malachowski et al. 2014, 2018). Twenty years ago, workshop participants sought to initiate or enhance their mentored research activities with virtually no focus on the curriculum, but this has changed substantially.

Changes to the curriculum often were initiated by developing research-rich classes in upper division or capstone courses to expose students to these approaches. Over time, lower division courses were targeted, frequently to better prepare students for independent research experiences. The next generation of curricula connected to research revolves around developing scaffolded, research-rich curricula using backward design principles. A scaffolded research-rich curriculum implies a structured curriculum that helps students gradually and intentionally build research skills and guides students to greater independence and ownership of their learning. Using this model, departments first map the current curriculum to their learning goals to identify redundancies and gaps (Malachowski 2017; Shanahan 2012). Embedding research into the curriculum using backward-designed, scaffolded approaches is gaining traction at institutions of all types, including research universities and community colleges. A current NSF-funded CUR project (NSF DUE 16-25354) involving 24 departments at 12 institutions over a four-year period involves doing just this type of work, and it is hoped that the results of this project will serve as models for other institutions. This approach presents cultural, resource, and planning challenges, but for those disciplines with many students, such as psychology and some biology departments, the time is ripe for research approaches that can accommodate many more students.

\section{Conclusion}

Over the past 25 years, UGR has taken root in many PUIs and become more important to faculty, students, and institutions. The inclusion of UGR as one of 10 high-impact practices has helped fuel these advances (Kuh 2008; Kuh et al. 2015; Kuh and Kinzie 2018; Mayhew et al. 2016), especially in spreading its use to new disciplinary fields. UGR is, above all, a collaboration between faculty and students, and the issues that need attention are frequently faculty driven. But faculty decisions have effects on students, most significantly the choice to remain student oriented while becoming more active in research and deciding whether improving student outcomes is the goal of the research program. As UGR flourishes at many institutions, it is clear that many faculty have chosen a students-first approach. Yet this is not universal, and there is a continued need to demonstrate that UGR serves the needs of all constituents: the students, the faculty, and the institution. The UGR community has come a long way in re-creating institutions as places that support the teacher-scholar model for faculty. The work continues to ensure creation of a world where students can thrive as student-scholars.

\section{References}

Aikens, Melissa L., Sona Sadselia, Keiana Watkins, Mara Evans, Lillian T. Eby, and Erin L. Dolan. 2016. "A Social Capital Perspective on the Mentoring of Undergraduate Life Science Researchers: An Empirical Study of Undergraduate-Postgraduate-Faculty Triads." CBE-Life Sciences Education 15(2): ar16. doi: $10.1187 /$ cbe. $15-10-0208$

Alkaher, Iris, and Erin L. Dolan. 2014. "Integrating Research into Undergraduate Courses." In Research Based Undergraduate Science Teaching, ed. Dennis W. Sunal et al., 403-434. Charlotte, NC: Information Age.

Astin, Alexander. 1977. Four Critical Years: Effects of College on Beliefs, Attitudes, and Knowledge. San Francisco: Jossey-Bass.

Astin, Alexander. 1993. What Matters in College? Four Critical Years Revisited. San Francisco: Jossey-Bass.

Awong-Taylor, Judith, Allison D'Costa, Greta Giles, Tirza Leader, David Pursell, Clay Runck, and Thomas Mundie. 2016. "Undergraduate Research for All: Addressing the Elephant in the Room." CUR Quarterly 37(1): 11-19. doi: 10.18833/curq/37/1/4

Boyer, Ernest L. 1990. Scholarship Reconsidered: Priorities of the Professoriate. Princeton: Carnegie Foundation for the Advancement of Teaching.

Corwin, Lisa A., Mark J. Graham, and Erin L. Dolan. 2015. "Modeling Course-Based Undergraduate Research Experiences: An Agenda for Future Research and Evaluation." CBE-Life Sciences Education 14(1). doi: 10.1187/cbe.14-10-0167

Eckel, Peter D., and Adrianna J. Kezar. 2003. Taking the Reins: Institutional Transformation in Higher Education. Westport, CT: Praeger and American Council on Education.

Fairweather, James S. 2002. "The Mythologies of Faculty Productivity: Implications for Institutional Policy and 
Decision Making." Journal of Higher Education 73: 26-48. doi: 10.1080/00221546.2002.11777129

Fairweather, James Steven. 2005. "Beyond the Rhetoric: Trends in the Relative Value of Teaching and Research in Faculty Salaries." Journal of Higher Education 76: 401-422. doi: $10.1080 / 00221546.2005 .11772290$

Hart Research Associates. 2013. "It Takes More Than a Major: Employer Priorities for College Learning and Student Success." Liberal Education 99(2): 22-29.

Hensel, Nancy H., and Elizabeth L. Paul (Eds.). 2012. Faculty Support and Undergraduate Research: Innovations in Faculty Role Definition, Workload, and Reward. Washington, DC: Council on Undergraduate Research.

Jacobson, Robert L. 1992. "Professors Who Teach More Are Paid Less." Chronicle of Higher Education, April 15: 16-18.

Karukstis, Kerry K., and Timothy E. Elgren. 2007. Developing and Sustaining a Research-Supportive Curriculum. Washington, DC: Council on Undergraduate Research.

Kotter, John P. 2012. Leading Change. Cambridge, MA: Harvard Business Press.

Kuh, George D. 2008. High-Impact Educational Practices: What They Are, Who Has Access to Them, and Why They Matter. Washington, DC: Association of American Colleges \& Universities.

Kuh, George D., Stanley O. Ikenberry, Natasha A. Jankowski, Timothy Reese Cain, Peter T. Ewell, Pat Hutchings, and Jillian Kinzie. 2015. Using Evidence of Student Learning to Improve Higher Education. San Francisco. Jossey-Bass.

Kuh, George, D., and Jillian Kinzie. 2018. "What Really Makes a 'High-Impact' Practice High Impact?" Inside Higher Ed. Accessed December 5, 2019. https://www.insidehighered.com/ views/2018/05/01/kuh-and-kinzie-respond-essay-questioninghigh-impact-practices-opinion

Kuh, George D., John H. Schuh, Elizabeth J. Whitt, Rosalind E. Andreas, James W. Lyons, C. Carney Strange, Lee E. Krehbiel, et al. 1991. Involving Colleges. San Francisco: Jossey-Bass.

Laursen, Sandra L. 2015. "Assessing Undergraduate Research in the Sciences: The Next Generation." CUR Quarterly 35(3): 9-14.

Laursen, Sandra, Anne-Barrie Hunter, Elaine Seymour, Heather Thiry, and Ginger Melton. 2010. Undergraduate Research in the Sciences: Engaging Students in Real Science. San Francisco: Jossey-Bass.

Lopatto, David. 2009. Science in Solution: The Impact of Undergraduate Research on Student Learning. Tucson, AZ: Research Corporation for Science Advancement/Council on Undergraduate Research.

Lopatto, David. 2010. "Undergraduate Research as a HighImpact Student Experience." Peer Review 12(2): 27-30.

Malachowski, Mitchell R. 1997. "Not All Research Is Equal: Student-Oriented versus Research-Oriented Approaches to Scholarship." CUR Quarterly 17(4): 182-185.

Malachowski, Mitchell R. 1999. "Promoting Undergraduate
Research in Non-Science Areas at Predominantly Undergraduate Institutions." CUR Quarterly 19(3): 126-130.

Malachowski, Mitchell R. 2001. "Should CUR Expand to Embrace All Disciplines?” CUR Quarterly 21(4): 156-158.

Malachowski, Mitchell R. 2003. "A Research-across-the-Curriculum Movement." In "Valuing and Supporting Undergraduate Research," ed. Joyce Kinkead, spec. issue, New Directions for Teaching and Learning, no. 93): 55-68. doi: 10.1002/tl.88

Malachowski, Mitchell R. 2004. "The Importance of Placing Students First in Designing Research Programs at Predominately Undergraduate Institutions." CUR Quarterly 24(3): 106-108.

Malachowski, Mitchell R. 2006. "Undergraduate Research as the Next Great Faculty Divide.” Peer Review 8(1): 26-27.

Malachowski, Mitchell R. 2010. "Unintended Consequences: Is CUR Undermining Teaching at Predominately Undergraduate Institutions?" CUR Quarterly 31(1): 32-36.

Malachowski, Mitchell R. 2012. "Living in Parallel Universes: The Great Faculty Divide between Product-Oriented and Process-Oriented Scholarship." In Hensel and Paul 2012, 7-18.

Malachowski, Mitchell R. 2013. "Undergraduate Research and Its Connection to Our Core Missions." In How to Get Started in STEM Research with Undergraduates, ed. Merle Schuh, 24-28. Washington, DC: Council on Undergraduate Research.

Malachowski, Mitchell R. 2017. "Saying Yes to Undergraduate Research." Chronicle of Higher Education, October 8. https://www.chronicle.com/article/Saying-Yes-to-Undergraduate/241396

Malachowski, Mitchell R., and Tammy J. Dwyer. 2011. "Requiring Research for All Students in a Major: Opportunities and Challenges." CUR Quarterly 32(1): 23-28.

Malachowski, Mitchell R., Nancy Hensel, Elizabeth L. Ambos, Kerry K. Karukstis, and Jeffrey M. Osborn. 2014. "The Evolution of CUR Institutes: From Serving Individuals to Serving Campuses, Systems, and Consortia." CUR Quarterly 35(1): 34-35.

Malachowski, Mitchell R., Jeffrey M. Osborn, Kerry K. Karukstis, Jillian Kinzie, and Elizabeth L. Ambos. 2018. "Institutionalizing Undergraduate Research and Scaffolding Undergraduate Research Experiences in the STEM Curriculum." In Best Practices for Supporting and Expanding Undergraduate Research in Chemistry, ed. Bridget L. Gourley and Rebecca M. Jones, ACS Symposium Series, vol. 1275, 259-269. Washington, DC: American Chemical Society. doi: 10.1021/bk-2018-1275.ch015

Malachowski, Mitchell R., and Marcus Webster. 2008. "Transforming Our Institutions into Research-Rich Environments." CUR Quarterly 29(2): 43-47.

Mayhew, Matthew J., Alyssa N. Rockenbach, Nicholas A. Bowman, Tricia A. D. Seifert, and Gregory C. Wolniak. 2016. How College Affects Students: 21st Century Evidence That Higher Education Works. San Francisco: Jossey-Bass.

National Academies of Sciences, Engineering, and Medicine (NASEM). 2015. Integrating Discovery-Based Research in the Undergraduate Curriculum: Report of a Convocation. Washington, DC: National Academies Press. doi: 10.17226/21851 
Nicols-Grinenko, Annemarie, Rachel B. Verni, Jennifer M. Pipitone, Christin P. Bowan, and Vanya Quinones-Jenab. 2017. "Building a Culture of Undergraduate Research: A Case Study." Scholarship and Practice of Undergraduate Research 1(2): 43-51. doi: 10.18833 /spur/1/2/13

Osborn, Jeffrey M., and Kerry K. Karukstis. 2009. “The Benefits of Undergraduate Research, Scholarship, and Creative Activity." In Broadening Participation in Undergraduate Research: Fostering Excellence and Enhancing the Impact, ed. Mary K. Boyd and Jodi L. Wesemann, 41-53. Washington, DC: Council on Undergraduate Research.

Pascarella, Ernest T., and Patrick T. Terenzini. 1991. How College Affects Students. San Francisco: Jossey-Bass.

Seymour, Elaine, Anne-Barrie Hunter, Sandra L. Laursen, and Tracee DeAntoni. 2004. "Establishing the Benefits of Research Experiences for Undergraduates in the Sciences: First Findings from a Three-Year Study." Science Education 88: 493-534. doi: $10.1002 /$ sce. 10131

Shanahan, Jenny O. 2012. "Building Undergraduate Research into the Curriculum.” In Hensel and Paul 2012, 68-76.
Wenzel, Thomas J. 2004. "Why Faculty Members Do Not Need to Directly Involve Students in Their Scholarly Work." CUR Quarterly 24(3): 109-110.

\section{Mitchell R. Malachowski}

University of San Diego, malachow@sandiego.edu

Mitchell R. Malachowski is professor of chemistry at the University of San Diego (USD) where he has been on the faculty since 1984. During his time at USD, he has worked with over 120 research students and published more than 50 papers, many of them with undergraduate coauthors. Malachowski was president of the Council on Undergraduate Research (CUR) in 2002-2003. He is the lead principal investigator for a $\$ 2$ million grant from the National Science Foundation (funded through CUR) to assist schools interested in developing more comprehensive undergraduate research programs and research-rich curricula. He was the recipient of the 2014 CUR Fellows Award and was named the 2014 CASE/ Carnegie Foundation California Professor of the Year.

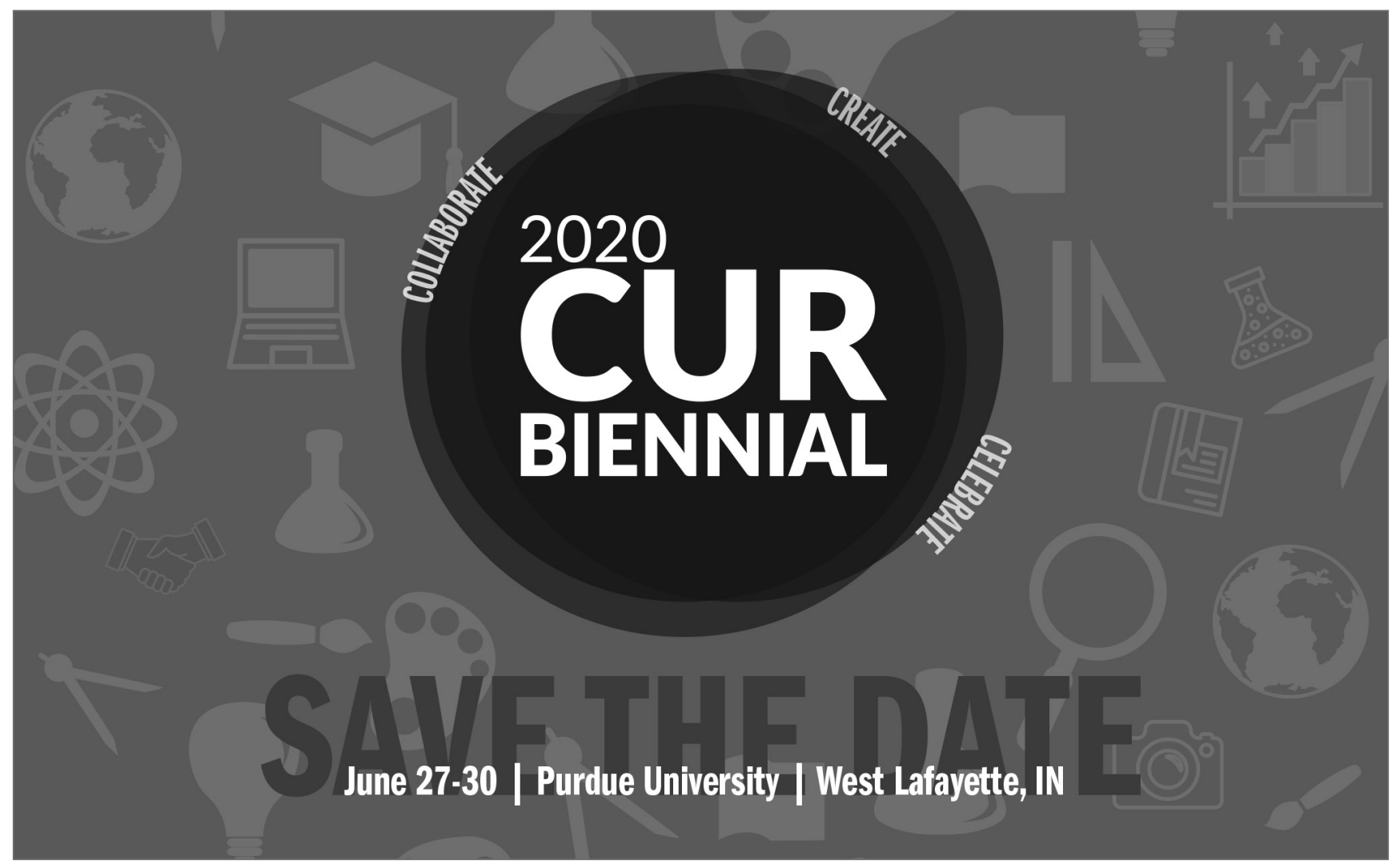

